REVISTA DE GESTÃO E SECRETARIADO

MANAGEMENT AND ADMINISTRATIVE

PROFESSIONAL REVIEW

ISSN: 2178-9010
Revista GeSec

São Paulo, SP, Brasil

v. 12 , n. 2, p. $273-300$

maio /ago. 2021

DOI: http://dx.doi.org/10.7769/gesec.v12i2.1157

\title{
Terceirização de tecnologia da informação e gestão de contratos no setor público: um estudo na SEFAZ/SE
}

\section{Outsourcing information technology and contract management in the public sector: a study at SEFAZ/SE}

\author{
Adriane Almeida do Sacramento ${ }^{1}$ \\ Maria Conceição Melo Silva Luft ${ }^{2}$ \\ Marcio Roque dos Santos da Silva ${ }^{3}$ \\ José Ednilson Matos Júnior ${ }^{4}$
}

\section{Resumo}

Este artigo tem como objetivo analisar o processo de terceirização de Tecnologia da Informação (TI) e a gestão dos contratos na Secretaria de Estado da Fazenda de Sergipe (SEFAZ/SE). Metodologicamente, realizou-se uma pesquisa de abordagem qualitativa, adotando a estratégia de estudo de caso único. Para a produção dos dados, aplicou-se um roteiro de entrevista semiestruturado junto a servidores ligados à área de TI. Constatou-se que, diferentemente das organizações privadas, o órgão público não apresenta a redução de custos e aspectos econômicos como principais motivadores para a terceirização. Apesar das desvantagens, considera-se o processo vantajoso e eficiente. Revela-se ainda que a SEFAZ/SE utiliza um arranjo de terceirização total, divergindo das recomendações da literatura; e identificou-se como principal fator de risco a dependência do fornecedor. Este estudo pode auxiliar no fornecimento de informações para governo, sociedade e gestores públicos sobre o processo de terceirização de TI e seus impactos no setor público.

Palavras-chave: Terceirização de Tecnologia da Informação. Gestão de contratos. Setor público. Secretaria de Estado da Fazenda.

\footnotetext{
${ }^{1}$ Mestre em Administração.

${ }^{2}$ Doutora em Administração, Docente no Programa de Pós-graduação em Administração da Universidade Federal de Sergipe (UFS).

${ }^{3}$ Mestrando em Administração no Programa de Pós-graduação em Administração da UFS.

${ }^{4}$ Mestrando em Administração no Programa de Pós-graduação em Administração da UFS.
} 


\begin{abstract}
This article aims to analyze the Information Technology (TI) outsourcing process and contract management at the Sergipe State Secretariat of Finance (SEFAZ/SE). Methodologically, a qualitative research was carried out, adopting the strategy of a single case study. For the production of the data, a semi-structured interview script was applied to servers connected to the IT area. It was found that, unlike private organizations, the public agency does not present cost reduction and economic aspects as the main motivators for outsourcing. Despite the disadvantages, the process is considered to be advantageous and efficient. It is also revealed that SEFAZ/SE uses a total outsourcing arrangement, diverging from the literature recommendations; and supplier dependency was identified as the main risk factor. This study can assist in providing information to government, society and public managers about the IT outsourcing process and its impacts on the public sector.
\end{abstract}

Keywords: Outsourcing of Information Technology. Contract management. Public sector. State Secretariat of Finance.

\title{
Introdução
}

É notório o impacto que a Tecnologia da Informação (TI) trouxe para as organizações, ocasionando mudanças na condução dos negócios e melhorias no desempenho organizacional. A TI pode ser considerada um dos componentes mais importantes dentro das empresas, não apenas operacionalmente, como também a nível estratégico (Albertin \& Albertin, 2008; Cherobini, 2017; Moreno, Coelho, \& Pitassi, 2020).

Concernente a isso, as organizações têm utilizado estrategicamente a terceirização da área de TI. Ela se configura por meio da transferência de funções e atividades de uma organização contratante para outras organizações prestadoras de serviços especializados, buscando alcançar objetivos e desempenhos predefinidos (Lacity \& Willcocks, 1998; Guedes \& Guadagnin, 2003; Lacity \& Willcocks, 2012; Lee, 2017; Carvalho, Poleto, \& Seixas, 2017), tendo em vista a obtenção de vantagem competitiva e considerando impactos empresariais e sociais (Bezerra, 2008; Trantopoulos, Krogh, Wallin, \& Woerter, 2017). A terceirização de TI pode ocorrer de diversas formas, desde o desenvolvimento e manutenção de softwares, gerenciamento de máquinas, telecomunicações, redes e servidores aos processos que dependem do suporte de TI, como compras e recursos humanos (Da Silva, Duarte, De Castro, \& Araújo, 2009; Lacity \& Willcocks, 2012; Lacity, 2017). 
A Administração Pública tem sido uma das principais contratantes dos serviços de terceirização de TI (Guarda, 2011; Tadeu \& Guimarães, 2017), tendo em vista que essa prática “[...] é reconhecida como um fator importante que contribui para a transparência do governo e a qualidade dos serviços públicos, dada a legislação que rege esses contratos e a quantidade de despesas relacionadas" (Guarda, Oliveira, \& Sousa Júnior, 2015, p. 82).

Afirma-se que as organizações públicas possuem especificidades que tornam esse processo singular e, muitas vezes, mais complexo do que nas empresas privadas. Assim, é necessário compreender a natureza dessas organizações para lidar com as dificuldades inerentes ao setor, utilizando métodos próprios e buscando soluções, mais bem adequadas, em modelos de referência de práticas bem-sucedidas adotadas por outras organizações públicas, além da observância da própria legislação e jurisprudência (Cruz, Andrade, \& Figueiredo, 2011; Guarda et al., 2015; Nunes, 2018).

Observa-se que a temática da terceirização de TI é de grande relevância para as organizações por se tratar de uma prática estratégica dentro dos negócios (Cristofoli, 2011; Poleto, 2012; Carvalho et al., 2017; Cherobini, 2017; Nunes, 2018). Ademais, existe uma escassez de estudos sobre o tema orientados ao setor público, o que dificulta a compreensão de um padrão de comportamento do fenômeno no setor (Lins, Duda Junior, \& Cunha, 2016).

Ainda nesta linha, no tocante a esfera estadual, Santos Filho (2009) destaca que a terceirização de TI surgiu como uma solução à antiga centralização dos respectivos serviços nas empresas estaduais de processamento de dados e existe uma tendência de descentralização do modelo de gestão da TI para um modelo híbrido. Com efeito, houve um crescimento do processo de terceirização de TI em empresas públicas, sobressaindo-se em algumas conforme sua importância estratégica e as características particulares inerentes ao tipo de organização, não só quanto às questões legais, que levam, muitas vezes, à adoção de soluções e métodos próprios, bem como a descentralização do modelo de gestão de TI em cada empresa estatal.

Em consonância, Mizael, Murad e Antonialli (2020) reforçam que ações como a descentralização do aparelho do Estado, terceirização dos serviços públicos e regulação estatal de atividades públicas conduzidas pelo setor privado se assentam no contexto da Administração Gerencial, transpondo práticas de mercado para o setor público. Para tanto, este artigo realiza o seguinte questionamento: como ocorre o processo de terceirização da tecnologia da informação e gerenciamento desses contratos na Secretaria de Estado da Fazenda de Sergipe (SEFAZ/SE)? Nesse contexto, este estudo objetiva analisar como ocorre o processo de terceirização de TI e a gestão dos contratos na Secretaria de Estado da Fazenda de Sergipe (SEFAZ/SE), a partir de um estudo de caso, na percepção dos gestores operacionais. 
Convém destacar que, no setor público, alguns estudos no Brasil acerca da temática investigaram as melhores práticas para o gerenciamento de contratos terceirizados de $\mathrm{TI}$ (Nunes, 2018), contemplando resultados que indicam a necessidade de repensar o processo burocrático como limitador da eficiência e qualidade da prestação do serviço. Já outros estudos, como o de Lins, Duda Júnior e Cunha (2016), realizaram uma revisão da literatura sobre a terceirização de Sistemas de Informação, constatando aspectos da segurança, dependência de fornecedores e perda das competências centrais de TI como riscos principais; foco nas core competencies, diminuição dos custos e melhoria qualitativa dos serviços como motivações; além da flexibilização das atividades de TI e acesso a novos mecanismos e habilidades como benefícios principais. Desse modo, tais estudos contribuem para a proposição desta pesquisa.

O texto está organizado em quatro seções, além dessa introdução. A segunda seção tratase da fundamentação teórica, abordando os elementos necessários a apreensão do processo de terceirização de TI; a terceira, corresponde aos procedimentos metodológicos, delineando os métodos e percurso adotados na pesquisa; a quarta seção apresenta a descrição e análise do caso; e por fim, a quinta, apresenta as considerações finais.

\section{Fundamentação Teórica}

Esta seção discute acerca dos conceitos gerais e do processo de terceirização, assim como as especificidades no tocante à terceirização de TI.

\subsection{Terceirização de Tecnologia da Informação}

O termo terceirização ou outsourcing, uma combinação de out e source, significa fonte externa. É uma forma de gestão que permite delegar a um agente externo a responsabilidade operacional de processos e serviços realizados, normalmente, pela própria organização (Franceschini, Galetto, Pignatelli, \& Varetto, 2003). No sentido mais amplo, terceirizar consiste numa forma de delegar a outras organizações processos ou atividades que não acrescentam valor ao negócio principal da empresa (Lee, 2017). Dito de outra forma, “[...] pode ser descrita como a realização de atividades, por um terceiro, que não constituem serviço público em sua essência, [...] que somente complementam o serviço" (Mizael, Murad \& Antonialli, 2020, p. 30). Por meio dela busca-se maior agilidade e eficiência dessas funções, possibilitando que a organização contratante concentre maiores esforços em atividades e processos que geram maior valor agregado (Laranjeira, 2012; Lee, 2017; Trantopoulos et al., 2017). 
Quando a empresa opta pela terceirização como forma de aumentar a qualidade e reduzir os custos, é necessária uma transformação na organização, que passa a se concentrar no core business, tendo como consequência melhores resultados e uma gestão otimizada e mais eficiente (Guarda, 2011; Guarda et al., 2015; Moreno et al., 2020). Dessa forma, Cristofoli (2011) afirma que a terceirização se tornou uma ferramenta estrutural fundamental para as organizações, fazendo parte integrante da estratégia das empresas e fortalecendo os negócios num ambiente complexo, competitivo e composto por mudanças rápidas e inesperadas.

No caso específico da terceirização de TI, não se trata de um fenômeno novo, já que teve suas origens nos anos 1960 e 1970, com os tradicionais time sharing, compartilhamento de tempo e recursos computacionais, e com a alocação de profissionais da área de TI. Entretanto a natureza da terceirização evoluiu, assumindo novas formas e foco, devido às mudanças tecnológicas e organizacionais (Grover, Cheon, \& Teng, 1996; Lee, Huynh, Kwok, \& Pi, 2003; Bergamaschi, 2004; Carvalho et al., 2017).

Muitas definições de terceirização de TI são encontradas na literatura e, apesar de algumas diferenças, existe um consenso de que ela se refere à transferência organizacional de funções dessa área. A definição adotada neste artigo, por ser considerada mais abrangente e próxima do campo de investigação, é a de Silva (2013) que define o processo como sendo a transferência ou delegação dos recursos e/ou funções de TI, antes provido internamente, de forma total ou parcial, para serem providos por terceiros externos à organização.

Com relação à abrangência da terceirização de TI, praticamente, todos os serviços e funções podem ser terceirizados, como: manutenção de hardware e software, programação, implementação de sistemas, treinamento de equipe e usuário, serviços de rede, operação de sistemas, segurança, suporte a usuários finais e soluções e-business (Bergamaschi, 2004; Gonzalez, Gasco, \& Llopis, 2005). Dessa forma, cada organização deve avaliar as suas necessidades específicas e a abrangência que o processo alcançará. Entretanto, Bernstorff e Cunha (1999), Lee (2017) e Cherobini (2017) defendem que algumas funções e serviços da área de TI não devem ser terceirizadas, entre eles: a liderança, a coordenação de projetos, e o direcionamento estratégico da TI; isto é, aspectos ligados à tomada de decisão, inteligência do processo e conhecimento do negócio, e ao Plano Diretor de Informática (PDI) ou Planejamento Estratégico da Tecnologia da Informação (PETI).

Considerando as diversidades de funções e serviços de TI que podem ser terceirizados, o tipo e os arranjos de terceirização efetuados tornam-se fundamentais para as organizações. Dibbern, Goles, Hirschheim e Jayatilaka (2004) apresentaram vários exemplos de classificações de arranjos, opções ou tipos de terceirização, com base em estudos de Lacity: 
- Lacity e Hirschheim (1993) definiram os seguintes tipos: Body-shop, onde a gestão utiliza a terceirização como forma de suprir as demandas de curto prazo, por exemplo, a contratação de programadores de computador; Gestão de projeto, em que terceirizase um projeto específico ou parte do trabalho de TI; e Terceirização total, onde o fornecedor é totalmente responsável por uma parte significativa do trabalho de TI.

- Lacity e Hirschheim (1995) oferecem uma taxonomia de opções relacionadas à decisão de tercerização: Terceirização total, onde ocorre a transferência de quase todas as atividades de TI ou aquelas que representam mais de $80 \%$ do orçamento de TI para um único fornecedor externo; Internalização total, na qual mantém-se mais de $80 \%$ do orçamento de TI para a realização das atividades internamente, mesmo depois de uma avaliação do mercado de Sistema de Informação (SI); Fornecimento seletivo, onde selecionam-se as funções de SI que serão providas por terceiros enquanto entre $20 \% \mathrm{e}$ $80 \%$ do orçamento é mantido para as atividades que serão realizadas internamente.

Além dos tipos e arranjos estruturais, diversas motivações levam as organizações a terceirizarem a área de TI. Apesar dessa diversidade, elas são, fundamentalmente, de origem econômica, técnica ou estratégica (Bergamaschi, 2004; Lee, 2017; Trantopoulos et al., 2017). Quando se trata de empresas privadas, as motivações mais expressivas são baseadas em razões econômicas, tanto no âmbito nacional quanto internacional (Prado \& Takaoka, 2002; Cunhas \& Dornelas, 2011; 2013). Nesse sentido, apesar de toda retórica do uso da terceirização como fonte estratégica, de longe, a redução de custos foi o motivo mais, comumemente, identificado por pesquisadores (Lacity, Khan, \& Willcocks, 2009).

No que se refere à terceirização no setor público, Cunha e Dornelas $(2011 ; 2013)$ e Cherobini (2017) afirmam que as maiores motivações estão associadas à escassez de recursos humanos e à necessidade de modernização para atender a demanda e oferecer melhores serviços à população. Essas diferenças tornam o processo de terceirização de TI em organizações públicas mais complexo (Santos Filho, 2009).

É necessário evidenciar também que o processo de terceirização de TI traz vantagens, benefícios e desvantagens que precisam ser considerados durante o planejamento e tomada de decisão quanto à abrangência e aos demais processos inerentes à terceirização. Grover, Cheon e Teng (1996) afirmam que o sucesso da terceirização de TI pode ser avaliado conforme os benefícios potencialmente alcançáveis, descritos a partir de três categorias: estratégicos, econômicos e tecnológicos. Quanto as vantagens, destacam-se: o aumento da produtividade, a possibilidade da contratação de mão de obra especializada, a redução dos custos, a concentração das atividades principais e melhoria na qualidade (Guarda, 2011; Bastos, 2014). 
Contudo, apesar das vantagens observadas com a terceirização de TI nas organizações, nem todas alcançam os benefícios desejados, já que algumas desvantagens podem trazer sérios problemas caso não sejam mitigadas (Bernstorff \& Cunha, 1999; Laranjeira, 2012; Lacity, 2017). Grover, Cheon e Teng (1994) afirmam que algumas desvantagens ocorridas durante o processo de terceirização de TI decorrem de fatores administrativos, de custos e/ou de conflitos de interesses.

Alguns estudos apresentam fatores e recomendações que devem ser observados para um processo exitoso de terceirização, como: a escolha do fornecedor, que deve possuir capacidade técnica e mercadológica, e domínio das atividades a serem executadas; evitar a terceirização de funções/setores diretamente envolvidos com a atividade principal da empresa; gerenciamento de clientes, gerenciamento de contratos, gerenciamento de riscos e de transição (Foina, 2011; Gonzalez et al., 2005; Lacity, 2017; Moreno et al., 2020).

No tocante, especificamente, aos contratos, eles devem ter um prazo mínimo de vigência e devem prever a realização de avaliações periódicas para verificar a qualidade dos serviços prestados, podendo culminar na extinção do contrato caso os serviços da contatada não estejam atendendo às expectativas mínimas de qualidade exigidas. Apesar das recomendações, afirmase que a Administração Pública, uma das principais contratantes da terceirização de TI, apresenta inconformidades contratuais e o não aproveitamento dos produtos entregues, além da falta de gerenciamento e fiscalização, adequados, dos contratos (Guarda, 2011; Guarda et al., 2015).

\subsection{Terceirização de TI no Serviço Público e os Riscos Envolvidos}

No Brasil, a história da terceirização de TI no setor público está associada às companhias estaduais de processamento de dados e ao enxugamento da máquina estatal. A maioria dos Estados adotava como modelo base uma estrutura centralizada para atender às demandas dos recursos de TI dos órgãos da Administração Pública, avançando, posteriormente, para um modelo híbrido (Santos Filho, 2009). Buscando, assim, uma maior eficiência em seus processos com vistas a oferecer soluções para problemas sociais peculiares à esfera pública (Tadeu \& Guimarães, 2017), de modo que na atualidade essa prática tem sido amplamente difundida nesse setor (Cherobini, 2017; Nunes, 2018).

Algumas especificidades acerca da terceirização no setor público envolvem: a obrigatoriedade de cumprir a legislação vigente, que influencia as decisões; as pressões políticas internas e externas, tais como, a cobrança por melhoria de desempenho, buscando a

Revista Gestão e Secretariado (GeSec), São Paulo, SP, 12(2), maio/ago., 2021, 273-300. 
diminuição do excesso de burocracia e da ineficiência da máquina administrativa; e a escassez de recursos humanos qualificados, considerando as regras mais restritivas de contratações desse ambiente (Cunha \& Dornelas, 2011; 2013; Kremic, Tukel, \& Rom, 2006; Cherobini, 2017; Tadeu \& Guimarães, 2017). Lima, Silva e Molinário (2013) acrescentam a esses motivadores a questão da opinião pública, aspecto relevante a ser observado.

Nesse mesmo sentido, as peculiaridades do serviço público abrangem outros motivadores, além daqueles apresentados pelas empresas privadas, entre eles, a rigidez da estrutura de cargos e carreiras, e a dificuldade de se estabelecer remuneração justa aos níveis de qualificação dos servidores (Santos Filho, 2009). Outrossim, declara-se que a melhor forma de atenuar as dificuldades inerentes ao setor é compreender melhor a sua natureza, adotar métodos próprios e localizar soluções em modelos de referência de práticas bem-sucedidas adotadas por outras organizações públicas, e na própria legislação e jurisprudência (Cruz et al., 2011). Mizael et al. (2020, p. 32) ressaltam que dois aspectos devem ser ponderados para que as contratações realizadas pelas organizações públicas sejam satisfatórias: por um lado, faz-se necessário a observância quanto aos ritos legais, visto que o poder público age conforme o que a lei prevê; por outro lado, [...] existe a necessidade de assegurar que as empresas licitantes possuam condições adequadas para concorrer, celebrar os contratos e prestar os serviços da maneira esperada".

Diante disso, o êxito da terceirização de TI em organizações públicas não depende exclusivamente do gerenciamento e da fiscalização dos serviços terceirizados, mas também da publicação e do cumprimento das normas que envolvem o processo de contratação, de modo que se possam reduzir os riscos existentes (Guarda, 2011). Isso significa que as organizações precisam estar devidamente preparadas para gerenciar os fatores de riscos, buscando identificálos, conhecê-los e avaliar o nível e impacto que eles podem provocar, evidenciando alternativas com o intuito de eliminar ou minimizar os resultados negativos (Santos Filho, 2009). A Figura 1 apresenta um resumo de alguns riscos relacionados à terceirização de TI de forma geral e especificamente no setor público.

\begin{tabular}{|c|c|c|c|c|}
\cline { 2 - 5 } \multicolumn{1}{c|}{} & $\begin{array}{c}\text { TERCEIRIZAÇÃO } \\
\text { DE TI }\end{array}$ & AUTORES & $\begin{array}{c}\text { TERCEIRIZAÇ̃̃O DE TI } \\
\text { NO SERVIÇO PÚBLICO }\end{array}$ & AUTORES \\
\hline \multirow{2}{0}{$\circlearrowright$} & $\begin{array}{c}\text { Qualificação de pessoal } \\
\text { do provedor }\end{array}$ & $\begin{array}{c}\text { Lacity, Khan e } \\
\text { Willcocks (2009) }\end{array}$ & Segurança das informações & $\begin{array}{c}\text { Santos Filho } \\
(2009)\end{array}$ \\
\hline
\end{tabular}




\begin{tabular}{|c|c|c|c|}
\hline $\begin{array}{l}\text { Não conformidade com } \\
\text { o contrato do provedor }\end{array}$ & \multirow{8}{*}{$\begin{array}{l}\text { Gonzalez, Gasco e } \\
\text { Llopis (2010) } \\
\text { Lacity (2017) } \\
\text { Cherobini (2017) }\end{array}$} & $\begin{array}{l}\text { Complexidade das } \\
\text { atividades/funções } \\
\text { terceirizadas }\end{array}$ & \multirow{8}{*}{$\begin{array}{l}\text { Cruz, Andrade e } \\
\text { Figueiredo (2011) } \\
\text { Cherobini (2017) } \\
\text { Nunes (2018) }\end{array}$} \\
\hline $\begin{array}{l}\text { Dependência excessiva } \\
\text { do fornecedor }\end{array}$ & & $\begin{array}{l}\text { Estabilidade financeira dos } \\
\text { fornecedores }\end{array}$ & \\
\hline $\begin{array}{l}\text { Perda de habilidades e } \\
\text { competências críticas }\end{array}$ & & $\begin{array}{l}\text { Especificidade da transação } \\
\text { ou dos recursos envolvidos }\end{array}$ & \\
\hline $\begin{array}{l}\text { Incapacidade de } \\
\text { adaptação às novas } \\
\text { tecnologias }\end{array}$ & & Descontinuidade tecnológica & \\
\hline Problemas de Segurança & & $\begin{array}{c}\text { Descumprimento da } \\
\text { legislação de licitações e } \\
\text { contratos da Administração } \\
\text { Pública }\end{array}$ & \\
\hline $\begin{array}{c}\text { Irreversibilidade da } \\
\text { decisão de terceirizada }\end{array}$ & & $\begin{array}{c}\text { A baixa qualidade e o serviço } \\
\text { custoso, oriundos do excesso } \\
\text { de burocracia. }\end{array}$ & \\
\hline Questões de pessoal & & - & \\
\hline $\begin{array}{l}\text { Mudança de fornecedor } \\
\text { ou quebra de contrato } \\
\text { pelo prestador de } \\
\text { serviço }\end{array}$ & & - & \\
\hline
\end{tabular}

Figura 1 - Riscos existentes na Terceirização de TI e na Terceirização de TI no Serviço Público Fonte: Elaborado pelos autores (2019).

Segundo a Constituição Federal, em seu artigo 37, inciso XXI, determina-se a exigência de licitações quando há a necessidade de contratação de obras, serviços e alienações no âmbito dos Poderes da União, dos Estados, do Distrito Federal e Municípios (Brasil, 1988). Esse processo é regulamentado pela Lei de Licitações e Contratos, nº 8.666 de 21 de junho de 1993, que disciplina o processo licitatório e de contratos, com o objetivo de instituir normas e instruir os processos de gestão e aquisição de produtos e serviços nas organizações públicas, garantindo o uso adequado dos recursos públicos (Brasil, 1993).

Sobre isso, Cherobini (2017) e Nunes (2018) consideram a importância do decreto 2.271/97, que versa sobre a informática como objeto de terceirização, no que tange às atividades de cunho executivo, e, portanto, ressaltam a incumbência da Administração Pública sobre as tarefas de cunho estratégico, não devendo essas atividades serem terceirizadas. Porém, com o avanço crescente da adoção dessa prática, percebe-se que esse decreto tem sido contrariado, gerando um sensível desafio no que diz respeito a segurança da informação, fato que requer um novo olhar para a denominada gestão de riscos (Cherobini, 2017). 
Desse modo, as organizações públicas devem, ao optarem pela terceirização de TI, elaborar, cuidadosamente, editais de licitação específicos, claros e concisos (Nunes, 2018) de modo que os serviços a serem adquiridos atendam as expectativas e necessidades do órgão, e que os preços estejam dentro do padrão do mercado, como exige a norma, além de efetuar um gerenciamento de contratos eficiente, cumprindo todas suas cláusulas.

Apesar de todos os cuidados tomados, até mesmo com cláusulas de contratos bem definidas e rígidas, as desvantagens e os riscos inerentes ao processo de terceirização ainda podem estar presentes, sendo primordial o acompanhamento e monitoramento, bem como a implementação de medidas protetoras às organizações, que devem ser de conhecimento dos gestores (Santos Filho, 2009). Corroborando, Nunes (2018) afirma que um bom mecanismo de controle é a elaboração correta de um Acordo de Nível de Serviço (ANS).

Segundo Martinez (1998), existe uma nova classe de teorias que se fundamentam no estudo das organizações na forma de contratos, buscando uma maior eficiência na sua definição e no seu monitoramento, entre essas novas teorias encontra-se a Teoria da Agência.

No caso da terceirização da área de TI, Santos Filho (2009) e Gomes (2014) afirmam que o resultado dos projetos de terceirização de TI é diretamente impactado pelos elementos que formam a base da Teoria da Agência, quais sejam: a assimetria da informação, o risco moral e o conflito de interesses. Nesse sentido, a elaboração de um contrato de terceirização de TI deve solucionar e evitar os problemas que podem surgir de acordo com esses elementos. Para Cherobini (2017, p. 10), a fim de evitar tais problemas, faz-se necessário “ [...] o uso de regras (definição de políticas de segurança), normas e boas práticas legais (cláusulas contratuais, transferência de riscos etc.), controle e monitoração (uso de metodologias) de forma mais efetiva".

Já Nunes (2018), sugere a atualização da legislação brasileira, de modo que a mesma possibilite uma melhor administração desses serviços, e que possa, dessa forma, repensar o processo burocrático, a fim de encontrar o equilíbrio entre as exigências normativas e a eficiência, uma vez que esse processo "[...] valoriza excessivamente aspectos que, embora importantes, não fortalecem os aspectos técnicos relacionados à qualidade dos serviços de TI" (Nunes, 2018, p. 16).

Especialmente no caso da Administração Pública, o processo de terceirização de TI envolve um montante significativo de recursos públicos (Guarda, 2011; Guarda et al., 2015). Com isso, torna-se relevante analisar o processo de terceirização de TI nessas organizações de modo que sua escolha e gestão sejam realizadas de forma eficiente e em benefício da qualidade dos gastos públicos e do "valor público" declarado.

Revista Gestão e Secretariado (GeSec), São Paulo, SP, 12(2), maio/ago., 2021, 273-300. 


\section{Procedimentos Metodológicos}

Este estudo é de abordagem qualitativa e de caráter exploratório-descritivo, pois teve por objetivo analisar um problema dentro da sua realidade, por meio da percepção dos membros envolvidos no fenômeno (Creswell, 2014). Nesse sentido, buscou-se analisar o processo de terceirização de TI e a gestão dos contratos na SEFAZ/SE, por meio da percepção dos gestores operacionais, participantes envolvidos no processo de produção de dados. O método de pesquisa adotado foi o estudo de caso único (Yin, 2015).

A organização investigada foi selecionada de acordo com os seguintes critérios: (1) pertencer ao setor público; (2) pertencer à esfera estadual; (3) ter serviços terceirizados na área de TI num período superior a 20 anos e contínuo; e (4) proporcionar uma facilidade de acesso e de informações. A decisão de escolha do Estado de Sergipe baseou-se, inicialmente, no fator localização, uma vez que a esfera federal concentra suas áreas de TI, basicamente, nas sedes dos órgãos, quase todos localizados na cidade de Brasília, o que limitaria a utilização de algumas fontes de evidência. Além disso, destaca-se o conhecimento, por parte de um dos pesquisadores, de órgãos estaduais que possuem contratos expressivos e ativos de terceirização da área de TI, entre eles, o órgão aqui estudado.

Como fonte principal de evidências, utilizou-se um roteiro de entrevistas semiestruturado previamente validado por dois servidores estaduais que trabalham na área de TI da Empresa Sergipana de Tecnologia da Informação - EMGETIS, vinculada à Secretaria de Estado da Administração - SEAD, além de um professor de Sistemas de Informação da Universidade Federal de Sergipe. Após os ajustes recomendados, passou-se para a aplicação final junto a servidores envolvidos no processo de tercerirização de TI do órgão objeto de investigação. Foram selecionados 2 entrevistados, sendo um representante dos servidores efetivos e outro representante dos terceirizados, ambos envolvidos com a Gerência de TI e com efetiva experiência na área. O primeiro participante foi a Superintendente responsável pelo setor de TI, no cargo desde janeiro de 2016. A servidora tem 37 anos, ensino superior nas áreas de Ciências da Computação e Direito, e mestrado em Administração Pública. O segundo, servidor terceirizado, trabalha no órgão há 23 anos, e atua como Gerente de Projetos, possuindo experiência e conhecimento de todo o processo de terceirização de TI da SEFAZ/SE. O entrevistado tem 50 anos, é pós-graduado e possui 27 anos de experiência na área de TI. Para assegurar os procedimentos éticos no tocante à proteção aos participantes da pesquisa, os entrevistados foram convidados a assinar um Termo de Consentimento Livre e Esclarecido 
(TCLE), concordando com sua participação voluntária que garantem, entre outras coisas, o sigilo da fonte e o anonimato.

De modo complementar, realizou-se observação direta, permitindo a coleta de informações adicionais e análise documental, onde buscou-se acesso a documentos que tratavam do processo de terceirização de TI, visando constatar a veracidade das informações obtidas nas entrevistas (Yin, 2015).

Para o tratamento dos dados, utilizou-se a técnica de Análise de Conteúdo de Bardin (2016), a partir do processo de categorização que, segundo a autora, é o mais utilizado. Dessa forma, definiu-se previamente as seguintes categorias apresentadas na seção de Análise e Descrição do caso: abrangência da terceirização da TI; motivadores para terceirização de TI; vantagens, desvantagens e benefícios encontrados na terceirização da TI; riscos identificados na terceirização de TI; e processo licitatório e gestão dos contratos.

\section{Análise e Descrição do caso}

A SEFAZ foi criada em $1^{\circ}$ de dezembro de 1936 pela Lei $\mathrm{n}^{\circ} 46$. Após algumas fusões e transformações teve sua composição definitiva em 1991. É um órgão integrante da administração direta do Estado de Sergipe que tem como atividade principal programar, organizar, executar e gerenciar as finanças públicas estaduais, arrecadação, fiscalização e aplicação, visando maximizar a receita e otimizar as despesas para o desenvolvimento políticoeconômico do estado e do bem-estar social do povo.

A Gerência Geral de Tecnologia da Informação é o setor responsável pelas atividades de TI, subordinada diretamente a Superintendência de Administração e Finanças. Ao todo, a Secretaria possui 1.300 (mil e trezentos) funcionários, dos quais 60 (sessenta) estão alocados na Gerência de Tecnologia da Informação, sendo que apenas 4 (quatro) são servidores efetivos e 56 (cinquenta e seis) são funcionários terceirizados.

\subsection{Abrangência da terceirização de TI}

Com relação à abrangência da terceirização de TI na SEFAZ/SE, constatou-se que o órgão possui um serviço de tecnologia bastante avançado e, praticamente, todos os serviços são terceirizados, como: análise, desenvolvimento e manutenção de sistemas e a sua aplicação, e o gerenciamento e suporte de redes. 
Conforme a literatura, todo e qualquer serviço de TI pode ser terceirizado, apesar de alguns autores defenderem que funções e serviços voltados à liderança, à coordenação de projetos e às questões estratégicas devem ser evitados. No caso em questão, observa-se uma terceirização total, tendo em vista que, de acordo com o Gerente de Projetos entrevistado, todos os serviços de TI são terceirizados desde 1992, inclusive, o número de servidores efetivos lotados na área de TI não chega nem a $10 \%$ do total de servidores do setor. Isso reforça os estudos de Bergamaschi (2004) e Santos Filho (2009) que afirmam que quase todas as atividades de TI podem ser terceirizadas. No entanto, vai de encontro aos estudos de Bernstorff e Cunha (1999), Lee (2017) e Cherobini (2017), que ratificam que os sistemas considerados estratégicos não devem ser terceirizados.

Segundo a Superintendente, existe uma tentativa de separar a área usuária e a terceirização através da criação de uma fábrica de software, onde os usuários demandam e o setor de TI executa. Todavia a tentativa não funciona de forma adequada, tendo em vista a falta de conhecimento dos usuários no momento de realizarem as solicitações, comprometendo a comunicação e, portanto, a plena execução de alguns projetos. Essa falha na comunicação, às vezes, não ocorre a depender do responsável da área de TI por aquela demanda, ou seja, o terceirizado responsável pelo pedido que possui mais conhecimento e liderança consegue atender de maneira mais efetiva.

Apesar disso, percebe-se que existe uma preocupação da participação de servidores efetivos em todo projeto novo que venha a ser desenvolvido, ligados à área de negócio, mantendo um alinhamento entre a área de TI e de negócio, como assinalado pelo Gerente de Projetos:

Para cada projeto é indicado uma pessoa da área de negócio para ser o gestor do sistema. O gestor de sistema participa junto à equipe de TIC [Tecnologia da Informação e Comunicação] alocada ao projeto, desde a sua definição até a implantação. A nossa metodologia de trabalho tem como atividade inicial a modelagem dos processos de negócios inerentes ao projeto e a definição dos requisitos. Nesta fase, a participação do gestor de sistemas é bastante efetiva. Durante a implementação da solução, a cada fase concluída, o gestor de sistemas faz a homologação e só após as devidas correções autoriza a publicação em Produção.

Além disso, esse gestor é responsável pelos treinamentos aos usuários, apoiados pelos servidores da TI, e por todas as manutenções corretivas e evolutivas após a implantação do sistema.

Embora a Secretaria possua terceirização total, aquela em que o fornecedor se responsabiliza totalmente por uma parte significativa das atividades de TI conforme Lacity e Hirschheim (1995), a propriedade do serviço terceirizado é do órgão, pois aquilo que é 
produzido pertence à SEFAZ/SE e é administrado por ela, apesar de ser desenvolvido por terceiro, reforçando a compreensão da essência do serviço público (Mizael et al., 2020).

\subsection{Motivadores para terceirização de TI}

Diversos estudos como os de Bernstorff e Cunha (1999), Prado e Takaoka (2002), Bergamaschi (2004), Lacity et al., (2009), Hamzah, Sulaiman e Hussein (2013) e Lacity (2017) apontam motivações, relacionadas a aspectos econômicos, técnicos ou estratégicos, que levam as organizações a buscarem a terceirização de TI.

No órgão investigado, os entrevistados apontaram diferentes motivações que levaram a terceirização de TI, associadas em síntese à conjuntura da época, à falta de qualificação dos servidores, e ao foco na área-fim. No tocante à conjuntura da época, o Gerente de Projetos declarou que a terceirização de TI nos órgãos do poder executivo estadual, de modo geral, teve início em 1992 devido a uma greve na antiga Companhia de Processamento de Dados de Sergipe (PRODASE), empresa responsável por atender as demandas de TI naquela época, que teve como consequência a paralisação de todos os serviços do governo estadual. Nas palavras do Gerente de Projetos:

\footnotetext{
A empresa responsável por atender as áreas de TIC dos órgãos estaduais era a PRODASE, atual EMGETIS, [Empresa Sergipana de Tecnologia da Informação], mas em 1991, a empresa entrou em greve paralisando todos os serviços do Estado. Nesse momento, o governo do Estado resolveu iniciar um processo de terceirização dos serviços da PRODASE e passou a alocar terceirizados tanto na sede quanto nos órgãos do Estado. Em 1992, firmou o primeiro contrato de terceirização.
}

No caso específico da SEFAZ/SE, a partir de 2000, os contratos de terceirização da área de TI passaram a ser geridos internamente e não mais por terceirizados contratados pelo Estado, conforme complementou o entrevistado.

Sobre a falta de qualificação dos servidores, a Superintendente destacou que os principais fatores para a terceirização de TI envolveram a falta de capacitação e treinamento para os servidores efetivos do quadro, diante da necessidade de qualificação para atuarem na área e da rápida evolução da TI. Ou seja, os funcionários da Secretaria tinham assumido as funções há quase 25 anos e não possuíam perfil e conhecimento técnico para a área, que apresentava necessidades de melhorias e de acompanhamento dos avanços das tecnologias.

Já quanto ao foco na área-fim, a demanda pela terceirização veio da área usuária, tendo em vista que não foram os técnicos e servidores da área de TI que perceberam a necessidade de apoio e suporte, mas os usuários da área-fim, não apenas para substituir os funcionários em greve, apontado pelo Gerente de Projetos, mas também para informatizar e agilizar os processos 
internos como indicado pela Superintendente. Essas motivações podem ser consideradas de ordem técnica conforme a revisão de literatura realizada por Lacity et al., (2009).

Além dessas razões, foram constatadas outras motivações não identificadas na literatura utilizada para a fundamentação teórica deste artigo. Uma delas foi destacada pelo Gerente de Projetos e está relacionada à garantia da continuidade dos serviços, precavendo-se de possíveis paralisações dos servidores efetivos que, eventualmente, venham a comprometer o cumprimento das atividades essenciais à manutenção dos serviços públicos, caso as atividades de TI fossem de responsabilidade interna. Esse motivo está associado a questões de cunho legal do serviço público, considerando que em caso de greve dos servidores efetivos e a consequente descontinuidade das atividades de TI, a possibilidade de contratação de mão-de-obra rápida para a substituição temporária é mais restrita. Além disso, quanto aos cargos e funções dos servidores efetivos, não é permitido a sua alocação em outras atividades que não estejam definidas nas atribuições dos cargos, mesmo que eles tenham capacidade técnica para desenvolver tais funções.

Em regra, identificou-se que o setor público não apresenta razões relacionadas a redução de custos e aspectos econômicos como principais determinantes da terceirização de TI, diferentemente da iniciativa privada, como apontam Prado e Takaoka (2002) e Lacity et al., (2009). Os motivos estão mais associados a questões técnicas que envolvem a própria tecnologia; aspectos estratégicos quanto a necessidade de manter os servidores efetivos com foco na área-fim; e questões de ordem legal (Mizael et al., 2020), atreladas ao modo de contratação de servidores e às atribuições dos cargos.

\subsection{Vantagens, desvantagens e benefícios encontrados na terceirização da TI}

A literatura categoriza as vantagens relativas ao processo de terceirização de TI em estratégicas, econômicas e tecnológicas (Grover et al., 1996). Questionada acerca das vantagens observadas com a terceirização de TI no órgão, a Superintendente destacou a eficiência dos serviços prestados pelos terceirizados, considerando os resultados e o tempo de conclusão dos trabalhos. Em suas palavras:

Em relação às vantagens eu acho que é muito mais eficiente. Em termos de resultado. Em termos de tempo de entrega. Eu não consigo imaginar servidores entregando o produto na mesma velocidade que se entrega os terceirizados. E olhe que os terceirizados daqui, eles como já têm muito tempo [...] acabam adquirindo muitos vícios, mas, mesmo assim, a velocidade daqui é muito maior.

Outra vantagem apontada é a garantia de continuidade dos serviços a partir da automatização dos processos de TI e a terceirização do setor, não afetados em momentos de 
greve de funcionários efetivos, como em anos anteriores. Afirma-se que "[...] como todos os processos estão automatizados, a gente não percebe uma queda na arrecadação com a greve. Essas demandas internas da máquina pública, elas não afetam a área-fim, porque elas estão terceirizadas" (Superintendente).

Como vantagem da terceirização de TI, o Gerente de Projetos acrescentou a possibilidade de ter técnicos mais qualificados e atualizados com as tendências do mercado, fato muito observado em reuniões, a nível nacional, com as secretarias de outros Estados, apesar de ter algumas situações que também funcionam bem sem nenhuma terceirização, como expresso em sua fala:

Participamos de muitas reuniões nacionais envolvendo as demais secretarias de Estados e existem várias formas de prestação de serviços de TIC. Tem locais [...] que são 100\% Estado, mesmo, e funciona bem. Por exemplo, Rio Grande do Sul a terceirização deles toda é feita com a Empresa de Processamento de Dados e funciona bem. [...] Tem alguns Estados, hoje, que trabalham de forma mesclada. [...] Para que? Pra ter essa garantia de que o serviço não vai ter descontinuidade, caso tenha uma greve, tenha alguma paralisação ou alguma coisa desse tipo. [...] Tem locais que é $100 \%$ terceirizado que é como o caso daqui que funciona bem também. [...] Então, as principais vantagens da terceirização são: garantia da continuidade do serviço em momentos de greve e técnicos mais atualizados no mercado.

A contratação de mão-de-obra mais qualificada, especializada e atualizada corrobora e sustenta o estudo de Bastos (2014) que constatou essa vantagem como uma das mais encontradas no que se refere à terceirização de TI no setor público. Em consonância, Lins et al. (2016) também observaram o acesso a novos recursos e habilidades. Além disso, ressalta-se a garantia da continuidade dos serviços, apontada pelos entrevistados anteriormente, também como aspecto motivador.

Além das vantagens identificadas, os entrevistados expuseram as desvantagens desse processo, tal como constatadas, principalmente, nos estudos de Bernstorff e Cunha (1999). Elas estão associadas a fatores administrativos, de custos e conflitos de interesses (Grover, Cheon, \& Teng, 1994). A Superintendente apontou como principal desvantagem a falta de comunicação entre os usuários finais e terceirizados, por conta da resistência interna dos servidores com os terceirizados e pela falta de comprometimento desses últimos, os quais tendem a executar apenas a solicitação sem a preocupação de estabelecer melhorias, qualidade e a satisfação do usuário final, caracterizando-se como fatores administrativos.

Já o Gerente de Projetos destacou como desvantagem a falta de poder de decisão dos terceirizados, considerando que a gestão do setor de TI deveria ser realizada por servidores efetivos, visto que somente eles possuem poder decisório. Os usuários finais possuem resistência em aceitar sugestões de terceirizados porque acreditam que eles não possuem compromisso e conhecimento do negócio, o que reflete fatores relativos a conflitos de 
interesses. Essa situação poderia ser mitigada pela transferência de gestão, como propôs o entrevistado:

Como experiência nossa, a gestão da área de TIC deve ser realizada por alguém vinculado ao governo, pois facilita nas tomadas de decisão. [...] é uma pessoa que tem que ter poder de decisão forte, para fazer a gestão ali. O pessoal que está do outro lado, que é da casa, começa a achar o seguinte: - "aquela pessoa que está sentada ali não sabe do meu negócio, não tem domínio efetivo sobre isso, quem sabe sou eu, quem sabe onde o sapato aperta sou eu, quem sabe o que tem que melhorar sou". Então, como essa pessoa vai chegar lá e definir prioridades, juntamente com a área do negócio?! [...] Seria uma maneira de minimizar as desvantagens de poder decisório (Gerente de Projetos).

Destaca-se que a Teoria da Agência pode ser empregada para analisar a relação entre o principal e o agente, neste caso, o contratante e o fornecedor, durante a realização das atividades contratadas. Essa análise objetiva identificar as falhas e os conflitos dessa relação (Caldas \& Cunha, 2005; Jensen \& Meckling, 1976). Corroborando e atestando o estudo de Gomes (2014), algumas desvantagens observadas decorrem de elementos como assimetria da informação, risco moral e conflitos de interesse que sustentam a Teoria da Agência.

$\mathrm{Na}$ SEFAZ/SE, algumas desvantagens estão associadas à assimetria de informação, tendo em vista a falha na comunicação e a falta de conhecimento do contratante sobre a parte técnica e do fornecedor sobre o negócio. Outras desvantagens estão relacionadas aos conflitos de interesses como os problemas de comunicação entre os usuários finais e terceirizados, a resistência interna dos servidores com os terceirizados e a falta de comprometimento dos contratados. Além disso, em algum grau, essas desvantagens estão associadas ao risco moral como a incapacidade técnica e a falta de comprometimento dos terceirizados, fatores que, muitas vezes, não são observados ou declarados antes da formalização do contrato.

Com relação aos benefícios alcançados com a terceirização de TI no órgão, a Superintendente destacou a agilidade dos serviços prestados pelos terceirizados e a garantia de continuidade dos serviços nos momentos de greve dos servidores efetivos, implicando em um benefício econômico (Grover et al., 1996). Destacou-se também a facilidade da substituição de funcionários nos serviços desempenhados, considerando a disposição de profissionais para a solução de problemas do órgão, o que não ocorre com os funcionários internos, ligados as funções estipuladas legalmente para o cargo. Já o Gerente de Projetos considera que o maior benefício da terceirização de TI na SEFAZ/SE é o nível da informatização alcançado: "Somos referência nacional em relação à integração de todos os módulos do Sistema Fazendário. Pelo que conhecemos somos a única Secretaria de Estado que possui tal nível de integração”. Essa informatização trouxe melhorias na qualidade dos serviços, tratando-se de um benefício tecnológico (Grover et al., 1996). 


\subsection{Riscos identificados na terceirização de TI}

Quanto aos riscos da terceirização de TI no órgão, buscou-se verificar os riscos identificados antes do processo de contratação e as ações realizadas para mitigá-los, considerando que o contratante deve ser capaz de identificar, avaliar e atenuar os riscos (Lacity $\&$ Willcocks, 2012). Buscou-se averiguar também como era feito o gerenciamento desses riscos e quais as ações de contingências desenvolvidas após o contrato realizado.

Constatou-se que, aparentemente, no processo inicial para a contratação não houve identificação dos riscos que envolvem o processo de terceirização, visto que os entrevistados relataram desconhecer essa situação. Nos contratos atuais, verificou-se uma preocupação em minimizar os efeitos dos riscos inerentes ao processo, entre eles a dependência do terceirizado como também pode ser observado no estudo de Lins et al. (2016), buscando documentar todas as atividades por meio de um conceito de fábrica de software, como traz a Superintendente:

Hoje se trabalha essa mitigação de riscos com a terceirização com a documentação mesmo, o que é que se imagina... eu consigo fazer um conceito de fábrica, e aí eu tirando uma pessoa ela não afeta o desenvolvimento como o todo. Então, eu percebo que isso está enraizado aqui. [...] Olha, eu consigo... um elemento sozinho... Um colaborador sozinho... ele não detém aquela informação toda, a informação está pulverizada. [...] Eu posso trocar um programador e não afeta o desenvolvimento.

O intuito, então, é garantir que a substituição de um contratado ou fornecedor não afete o andamento das atividades. Esse risco também foi constatado por Gonzalez, Gasco e Llopis (2010), Lacity et al. (2009) e Guarda (2011).

Além disso, "Há uma cláusula contratual que se preocupa com a exclusiva propriedade dos códigos-fonte pela SEFAZ" (Gerente de Projetos), permitindo que qualquer técnico possa continuar o desenvolvimento e a manutenção dos sistemas. Isso corrobora e reafirma o estudo de Santos Filho (2009) que analisou os riscos inerentes a terceirização de TI em órgãos públicos da administração tributária. Evidencia-se também o risco associado à segurança das informações, a partir de uma cláusula específica que trata da confidencialidade das informações e da manutenção de procedimentos que limitam o acesso aos sistemas tributários a um grupo restrito, visto que a Secretaria trabalha com dados sigilosos.

Sobre as ações de contingências, há dois direcionamentos evidenciados nas falas dos entrevistados: para o Gerente de Projetos existe um plano de contingência relacionado à substituição dos técnicos ou ao cancelamento do contrato em caso de vazamento de informações; e para a Superintendente não existe um plano específico, mas uma disputa interna entre terceirizados e efetivos quanto o acesso às informações: 
Contratualmente, poderá haver substituição do técnico ou até cancelamento do contrato. As áreas responsáveis pela administração do contrato são as Superintendências de Tecnologia da Informação e a de Administração e Finanças (Gerente de Projetos).

O plano de contingência não existe. Mas quem se sente responsável... Esse assunto está na disputa entre os servidores efetivos e os terceirizados. É um ponto de disputa. Porque os efetivos, eles se sentem os donos da informação, até porque as informações aqui são protegidas pelo sigilo fiscal (Superintendente).

A partir da Teoria da Agência, identificou-se o risco relacionado ao número de fornecedores que pode causar um aprisionamento (lock-in) nos casos em que o contratante se torna dependente de um fornecedor específico (Santos Filho, 2009). Ademais, observa-se o oportunismo visto a seleção adversa, considerando a possibilidade da contratação de terceirizados que não possuem capacidade técnica adequada. Com isso, sinaliza-se que a Teoria da Agência pode contribuir para a identificação de riscos associados à terceirização de TI (Santos Filho, 2009; Gomes, 2014).

De modo geral, existem procedimentos que visam minimizar alguns riscos relacionados à terceirização de TI na SEFAZ/SE, no tocante à segurança das informações, à inflexibilidade dos contratos, à descontinuidade tecnológica e à falta de confiança. A Superintendente acrescenta que com a Lei da Transparência (Lei Complementar 131/2009) as informações passaram a ser públicas e os riscos de acesso indevido tornaram-se menos relevantes.

\subsection{Processo licitatório e gestão dos contratos}

A demanda inicial da necessidade de algum serviço de TI a ser terceirizado surge da Superintendência de TI e é repassada para a análise do Secretário. Com a demanda aprovada, a Assessoria Jurídica da Superintendência Geral de Administração e Finanças prepara os documentos necessários para a análise técnica da EMGETIS e posterior verificação da Procuradoria Geral do Estado. Por conseguinte, dar-se início aos trâmites referentes à operacionalização do processo licitatório (Mizael et al., 2020) conforme relatou o Gerente de Projetos. Isso se deve ao fato de se tratar de uma área bastante técnica e específica, dificultando a análise da viabilidade dessa necessidade por outras áreas do órgão.

Segundo a Superintendente, a SEFAZ/SE possui uma forma diferenciada de contratação, utilizando-se contrato de gestão com o Sergipe Parque Tecnológico SERGIPETEC, que consiste em uma Organização Social Estadual - OS, cuja missão é promover o empreendedorismo com foco na inovação, competitividade e gestão do conhecimento, trabalho e renda; e trabalha em conjunto com a Secretaria Estadual do Desenvolvimento Econômico, da Ciência e Tecnologia - SEDETEC, fazendo parte do sistema 
de inovação do Estado (SERGIPETEC, online). Por se tratar de uma OS, a contratação ocorre por meio de inexigibilidade, uma forma de contratação direta prevista na Lei de Licitações e Contratos (Brasil, 1993). O órgão considera essa forma mais barata do que um processo licitatório comum, visto que não possui fins lucrativos, disponibilizando uma taxa de administração mais acessível além da facilidade na contratação.

Há uma definição clara das responsabilidades e penalidades previstas com o descumprimento do contrato. Entretanto, conforme os entrevistados, a contratação in house, cujos terceirizados atuam dentro do órgão e de forma contínua, gera certa informalidade tornando confusa a relação com os terceirizados. Essa relação pessoal leva os terceirizados a pleitearem do próprio órgão responsabilidades indevidas, como questões relativas ao atraso de pagamentos e necessidades de treinamentos por exemplo. Isso fica evidente nas falas dos entrevistados:

$\mathrm{O}$ fato de a gente trabalhar dentro do cliente acaba que tem hora que ninguém sabe nem quem é quem. Então, às vezes, mistura mesmo. Apesar de eu estar aqui há 24 anos, ser terceirizado há 24 anos, tem gente que olha e pensa, hoje, que sou funcionário da casa (Gerente de Projetos).

Então, na teoria sim, na teoria eles são servidores do SERGIPETEC, eles são regidos por contrato. O contrato é feito por lá, o acordo coletivo é feito por lá, a gente não interfere nessa relação trabalhista. A nossa relação com o SERGIPETEC é financeira. Essa relação, como já tem muito tempo, eles acabam deixando muito na mão da gente algumas funções. Então acaba que é muito fácil virar uma relação pessoal com os terceirizados. [...] Então, a gente acaba tendo uma ingerência muito grande no contrato porque uma reclamação nossa pode significar uma alteração daquela pessoa [...] (Superintendente).

É necessário destacar que a SEFAZ/SE ainda possui alguns serviços associados à EMGETIS, principalmente na área de suporte, que não se trata de terceirização, mas de parceria, por se tratar de um órgão de Estado, segundo a Superintendente.

No tocante à forma de acompanhar e mensurar o desempenho da terceirizada (gestão dos contratos), existe um procedimento mensal realizado para medir a produtividade das atividades contratadas e realizadas, como relata o Gerente de Projetos: "Mensalmente, o SERGIPETEC define com a SEFAZ quais são os serviços que serão realizados, os quais são medidos por ponto de função. E no final do mês é emitido um relatório sobre os serviços que foram realizados". Entretanto, para a Superintendente, independentemente da produção mensal, considera-se a terceirização de TI essencial dentro da Secretaria, apresentando resultados sempre positivos. Nesse sentido, não há uma preocupação em medir e analisar formalmente a produção da terceirizada, visto que que os benefícios são claros, apesar de considerar que essa postura possa ser prejudicial.

Dessa forma, as renovações contratuais vêm ocorrendo automaticamente, considerando a satisfação com os serviços prestados pelos terceirizados e a garantia de continuidade das 
atividades de TI do órgão, conforme destacado pelos entrevistados. Todavia o Gerente de Projetos esclarece que, legalmente, o contrato é feito para um período de cinco anos, correspondendo, de acordo com a literatura, a um contrato de longa duração (Dibbern et al., 2004), e renovado anualmente, tendo critérios como a qualidade dos serviços prestados e o custo avaliados.

Por fim, os entrevistados relataram suas percepções sobre a terceirização de TI em órgãos públicos. Segundo a Superintendente, o processo nessas organizações é fundamental, principalmente, na área de suporte, tornando-a mais robusta. Entretanto é importante avaliar o limite da terceirização e a participação efetiva de servidores como gestores dos projetos de TI, como explica:

[...] eu acho que o grande segredo é até onde eu devo ir com a terceirização e até onde eu devo colocar servidores. [...] Se eu tivesse os gerentes de projetos servidores e tivesse tipo a execução, mesmo, e o suporte terceirizados, pra mim, hoje, eu imagino que esse modelo é um bom modelo [...] porque a gerência consegue andar bem nos dois mundos, ela consegue com mais facilidade ir na área usuária e consegue trazer o que tem mais de inovação e aí eu trago a execução com a terceirização.

Já o Gerente de Projetos afirma que a terceirização de TI é viável caso a gestão seja realizada por servidores efetivos e o corpo técnico, que desenvolve e desempenha efetivamente as atividades, composto por terceirizados. Essa viabilidade pode ser observada a partir dos benefícios da terceirização quanto a continuidade e qualidade dos serviços prestados, mediante a busca constante por qualificação profissional dos terceirizados, muitas vezes, não apresentada por funcionários efetivos.

A Figura 2 apresenta uma síntese do caso da SEFAZ/SE acerca do processo de terceirização de TI e gestão de contratos.

\begin{tabular}{|c|c|}
\hline $\begin{array}{c}\text { CATEGORIAS } \\
\text { ANALÍTICAS }\end{array}$ & \multicolumn{1}{c|}{ ELEMENTOS DE ANÁLISE IDENTIFICADOS } \\
\hline $\begin{array}{c}\text { Características da } \\
\text { empresa }\end{array}$ & $\begin{array}{l}\text { Ónão do Poder Executivo, criado em } 1^{\circ} \text { de dezembro de 1936; } \\
\text { - Tem como função programar, organizar, executar e gerenciar as finanças públicas } \\
\text { estaduais, arrecadação, fiscalização e aplicação; } \\
\text { - Possui 1300 funcionários; } \\
\text { - O setor de TI é chamado de Gerência Geral de Tecnologia da Informação, possui } 60 \\
\text { funcionários lotados (4 servidores efetivos e 56 terceirizados). }\end{array}$ \\
\hline $\begin{array}{c}\text { Abrangência da } \\
\text { Terceirização de }\end{array}$ & $\begin{array}{l}\text { - A terceirização de TI ocorre desde 1992; } \\
\text { - Entre os serviços terceirizados estão análise, desenvolvimento e manutenção de } \\
\text { sistemas e sua aplicação, e o gerenciamento e suporte de redes; }\end{array}$ \\
\hline $\begin{array}{c}\text { - Utiliza terceirização total. } \\
\text { Motivadores para }\end{array}$ & $\begin{array}{l}\text { - A demanda inicial da terceirização partiu da área usuária; } \\
\text { - Dentre os motivadores, destaca-se: a descontinuidade dos serviços por causa de greve } \\
\text { deflagrada pelos servidores efetivos; a falta de qualificação e de perfil técnico dos } \\
\text { servidores efetivos; a falta de treinamento dos servidores efetivos; a necessidade de } \\
\text { informatizar os processos. }\end{array}$ \\
\hline $\begin{array}{c}\text { Vantagens, } \\
\text { Desvantagens e } \\
\text { Benefícios }\end{array}$ & $\begin{array}{l}\text { Vantagens: eficiência dos serviços prestados; automatização dos processos que gerou } \\
\text { a garantia da continuidade dos serviços, no caso de greves; possibilidade de ter } \\
\text { técnicos mais qualificados e atualizados; agilidade no atendimento do suporte ao }\end{array}$ \\
\hline
\end{tabular}

Revista Gestão e Secretariado (GeSec), São Paulo, SP, 12(2), maio/ago., 2021, 273-300. 


\begin{tabular}{|c|c|}
\hline $\begin{array}{l}\text { encontrados na } \\
\text { terceirização de TI }\end{array}$ & $\begin{array}{l}\text { usuário; garantia de atendimento de suporte contínuo; facilidade da substituição de } \\
\text { funcionários nas atividades e serviços desempenhados; } \\
\text { - Desvantagens: falta de comunicação e conflitos entre os usuários finais e os } \\
\text { terceirizados; resistência interna dos servidores com os terceirizados; falta de } \\
\text { comprometimento dos terceirizados; } \\
\text { - Benefícios: agilidade dos serviços prestados pelos terceirizados; agilidade na } \\
\text { substituição de técnicos, evitando a descontinuidade das atividades e dos serviços; } \\
\text { nível da informatização alcançado. }\end{array}$ \\
\hline $\begin{array}{c}\text { Riscos identificados } \\
\text { na terceirização de } \\
\text { TI }\end{array}$ & $\begin{array}{l}\text { - Processo inicial: para contratação não houve identificação dos riscos que envolvem o } \\
\text { processo de terceirização; } \\
\text { - Processo em andamento: dependência do terceirizado e, consequentemente, a } \\
\text { possibilidade de descontinuidade dos trabalhos; segurança das informações; } \\
\text { inflexibilidade dos contratos; descontinuidade tecnológica; e falta de confiança; } \\
\text { - Análise dos riscos, considerando a ação de contingência tomada, onde se definiu a } \\
\text { propriedade exclusiva dos códigos-fonte da SEFAZ/SE, permitindo que qualquer } \\
\text { técnico possa continuar o desenvolvimento e a manutenção dos sistemas. }\end{array}$ \\
\hline $\begin{array}{l}\text { Processo licitatório } \\
\text { e gestão dos } \\
\text { contratos de TI }\end{array}$ & $\begin{array}{l}\text { - Processo licitatório: utiliza uma forma diferenciada de contratação por meio de uma } \\
\text { Organização Social Estadual - OS; a forma de contratação ocorre por inexigibilidade; } \\
\text { facilidade para a contratação; } \\
\text { - Gestão de contratos: define-se as responsabilidades e penalidades com o } \\
\text { descumprimento do contrato; é realizado um procedimento mensal para medir a } \\
\text { produtividade das atividades contratadas e realizadas; as renovações contratuais } \\
\text { ocorrem automaticamente. }\end{array}$ \\
\hline
\end{tabular}

Figura 2 - Síntese do caso da SEFAZ/SE

Fonte: Elaborado pelos autores (2019).

\section{Considerações Finais}

O presente artigo teve por objetivo analisar o processo de terceirização de TI e a gestão dos contratos na SEFAZ/SE, na percepção dos gestores operacionais. Os achados da pesquisa possibilitaram constatar que a SEFAZ/SE terceiriza praticamente todas as atividades de TI, configurando uma terceirização total, incluindo os sistemas que envolvem atividades da áreafim, o que diverge de estudos que afirmam que atividades estratégicas, de coordenação e liderança devem ser evitadas. Isso pode ser, em alguma medida, prejudicial para o órgão, visto que os riscos identificados envolvem a segurança das informações e garantia da continuidade da prestação dos serviços, associados à dependência do fornecedor. Como forma de atenuá-los, a SEFAZ/SE determina em seus contratos a propriedade dos códigos-fonte.

Evidencia-se que o órgão utiliza uma forma diferenciada de contratação, por meio de OS. E para a gestão dos contratos são definidas, claramente, as responsabilidades e penalidades quanto ao descumprimento do contrato, realizando mensalmente a mensuração da produtividade das atividades contratadas e realizadas. As razões dessa terceirização relacionamse a fatores de ordem técnica ou estratégica, depreendendo que a terceirização de TI no setor público é vantajosa e pode trazer benefícios estratégicos, tecnológicos e econômicos. Algumas desvantagens, ainda que em menor número, também foram constatadas. 
Embora se trate de um processo semelhante ao de empresas privadas, as especificidades legais do setor público trouxeram novos aspectos relacionados, por exemplo, às motivações, como a impossibilidade de contratação imediata ou substituição dos servidores por motivo de greve.

De modo geral, os entrevistados consideram a terceirização de TI fundamental no setor público, principalmente, para os serviços de suporte e atendimento ao usuário, mas defendem que o modelo ideal deveria envolver a contratação de terceiros apenas para as atividades técnicas, mantendo a gestão dos projetos de TI sob responsabilidade dos servidores efetivos, com conhecimento técnico e qualificação para, inclusive, avaliar os serviços prestados.

Os resultados do estudo indicaram que a terceirização de TI no setor público é uma realidade e, muitas vezes, uma necessidade, seja por questões técnicas ou para atender uma exigência determinada por lei, e que as vantagens e benefícios alcançados superam as dificuldades e desvantagens associadas ao processo. O órgão investigado considerou os benefícios que a terceirização da TI trouxe e, apesar de destacar o nível de qualidade dos sistemas da SEFAZ/SE, há uma clara dependência dos técnicos terceirizados, quanto ao conhecimento dos aplicativos voltados às questões estratégicas.

Dessa forma, tem-se que o problema de pesquisa foi respondido uma vez que o processo de terceirização de TI foi descrito assim como a operacionalização da gestão de contratos, destacando-se a forma diferenciada de contratação por meio de uma Organização Social Estadual com clareza de responsabilidades. Ademais, o estudo apontou aspectos relevantes para análises acerca da temática que, dentro das limitações das técnicas de investigação e considerando a realidade de cada organização pública, não podem ser generalizados, mas indicam direcionamentos para futuras investigações. Assim, sugere-se a ampliação do estudo para outros órgãos públicos, da esfera federal ou de outros estados, propondo um estudo quantitativo que busque verificar aspectos acerca do processo de terceirização de TI e gestão de contratos, desde as motivações aos riscos frequentemente identificados nessas organizações.

Além da contribuição acadêmica, em termos de difusão e contribuição ao debate, este artigo pode auxiliar no fornecimento de informações para governo, sociedade e gestores públicos sobre o processo de terceirização da TI e seus impactos no setor público.

\section{Referências}


Albertin, A. L., \& Albertin, R. M. M. (2008). Benefícios do uso de tecnologia de informação para o desempenho empresarial. Revista de Administração Pública, Rio de Janeiro, 42(2), 275-302.

Bardin, L. (2011). Análise de conteúdo. São Paulo: Edições 70, 2016.

Bastos, E. G. (2014). Terceirização e Inovação no Serviço Público: estudo de caso em uma Instituição Federal de Ensino Superior. 87 f. Dissertação (Mestrado Profissional em Administração) - Fundação Pedro Leopoldo, Pedro Leopoldo.

Bergamaschi, S. (2004). Modelos de gestão da terceirização de Tecnologia da Informação: um estudo exploratório. 179 f. Tese (Doutorado em Administração) - Universidade de São Paulo, São Paulo.

Bernstorff, V. H., \& Cunha, J. C. (1999). O que as organizações buscam e alcançam com a terceirização em Tecnologia da Informação (TI). In Anais, 23 Encontro da Associação Nacional de Pós-Graduação e Pesquisa em Administração, Foz do Iguaçu: EnANPAD.

Bezerra, A. K. P. (2008). Impactos da terceirização não-seletiva em tecnologia da informação: um estudo na Companhia Pernambucana de Gás. 130 f. Dissertação (Mestrado em Administração) - Universidade Federal de Pernambuco, Recife.

Brasil. (1988). Constituição da República Federativa do Brasil de 1988. Brasília/DF: 5 out.

Brasil. (1993). Lei $n^{\circ}$ 8.666, de 21 de junho de 1993. Regulamenta o art. 37, inciso XXI, da Constituição Federal, institui normas para licitações e contratos da Administração Pública e dá outras providências. Brasília/DF: 21 jun.

Caldas, M. P., \& Cunha, M. P. (2005). Ecologistas e Economistas Organizacionais: O Paradigma Funcionalista em Expansão no Final do Século XX. Revista de Administração de Empresas, São Paulo, 45(3), 65-69.

Carvalho, V. D. H, Poleto, T., \& Seixas, A. P. C. (2017). Information technology outsourcing relationship integration: a critical success factors study based on ranking problems (P. $\gamma$ ) and correlation analysis. Expert Systems, 35(1).

Cherobini, T. M. (2017). Terceirização de serviços de TI: aspectos de segurança. $20 \mathrm{f}$. Trabalho de Conclusão de Curso (Especialização em Governança de Tecnologia da Informação) Universidade do Sul de Santa Catarina, Santa Catarina.

Creswell, J. W. (2014). Research Design: qualitative quantitative and mixed approaches. (4rd ed.). Thousand Oaks: Sage.

Cristofoli, F. (2011). Um estudo sobre a gestão da terceirização de serviços de tecnologia da informação baseados em modelos de governança. 249 f. Tese (Doutorado em Administração) - Universidade de São Paulo, São Paulo. 
Cruz, C. S., Andrade, E. L. P, \& Figueiredo, R. M. C. (2011). Processo de contratação de serviços de tecnologia da informação para organizações públicas. $\mathrm{N}^{\mathrm{o}} 7$. Brasília: Ministério da Ciência e Tecnologia. Secretaria de Política de Informática.

Cunha, M. X. C., \& Dornelas, J. S. (2011). Aspectos e Fatores Motivadores da Terceirização de Sistemas de Informação no Setor Público: Um Estudo em Instituições Públicas de Alagoas. 213 f. Tese (Doutorado em Administração) - Universidade Federal de Pernambuco, Recife.

Cunha, M. X. C., \& Dornelas, J. S. (2013). Aspectos e Fatores Motivadores da Terceirização de Sistemas de Informação no Setor Público: Um Estudo em Instituições Públicas de Alagoas. In Anais, 4 Encontro de Administração da Informação, Bento Gonçalves: EnADI.

Da Silva, M. A., Duarte, R. G., De Castro, J. M., \& Araújo, A. R. (2009). Outsourcing de TI e redefinição do papel da subsidiária: um estudo comparativo entre as subsidiárias brasileira e indiana de uma multinacional americana. Journal of Information Systems and Technology Management, São Paulo, 6(2), 173-202.

Dibbern, J., Goles, T., Hirschheim, R., \& Jayatilaka, B. (2004). Information Systems Outsourcing: A Survey and Analysis of the Literature. The Data Base for Advances in Information Systems, Fall, 35(4).

Foina, P. R. (2011). Tecnologia da informação: planejamento e gestão. (2a ed.). São Paulo: Atlas.

Franceschini, F., Galetto, M., Pignatelli, A., \& Varetto, M. (2003). Outsourcing: guidelines for a structured approach. Benchmarking: An International Journal, 10(3), 246-260.

Gomes, G. S. (2014). Análise de projetos terceirizados de TI sob a ótica das teorias da agência e de desenvolvimento de grupos. 138 f. Dissertação (Mestrado em Administração e Negócios) - Pontifícia Universidade Católica do Rio Grande do Sul, Porto Alegre.

Gonzalez, R., Gasco, J., \& Llopis, J. (2005). Information systems outsourcing success factors: a review and some results. Information \& Management, 43(7), 821-834.

Gonzalez, R., Gasco, J., \& Llopis, J. (2010). Information systems outsourcing reasons and risks: a new assessment. Industrial Management \& Data Systems, 110(2), 284-303.

Grover, V., Cheon, M. J., \& Teng, J. T. C. (1994). A descriptive study on the outsourcing of information systems functions. Information \& Management, 27(1), 33-44.

Grover, V., Cheon, M. J., \& Teng, J. T. C. (1996). The effect of service quality and partnership on the outsourcing of information systems functions. Journal of Management Information Systemas, Armonk, 12(1), 80-116. 
Guarda, G. F. (2011). Análise de contratos de Terceirização de TI na Administração Pública Federal sob a ótica da Instrução Normativa n 04. 118 f. Dissertação (Mestrado em Engenharia Elétrica) - Universidade de Brasília, Brasília.

Guarda, G. F., Oliveira, E. C., \& Sousa Júnior, R. T. (2015). Analisys of it outsourcing contracts at the TCU (Federal Court of Accounts) and of the legislation that governs these contracts in the Brazilian Federal Public Administration. Journal of Information Systems and Technology Management, 12(1), 81-106.

Guedes, A. L., \& Guadagnin, R. V. (2003). A gestão de projetos como aprimoramento da terceirização. Informática Pública, 5(1), 65-78.

Hamzah, A. K., Sulaiman, R., \& Hussein, W. N. (2013). A review on IT outsourcing approach and a proposed IT outsourcing model for Malaysian SMEs in e-Business adoption. In Anais, Research and Innovation in Information Systems (ICRIIS): International Conference on. IEEE, 521-526.

Jensen, M., \& Meckling, W. (1976). Theory of the firm: managerial behavior, agency costs and ownership structure. Journal of Financial Economics, 3(4), 305-360.

Kremic, T., Tukel, O. I., \& Rom, W. O. (2006). Outsourcing decision support: a survey of benefits, risks, and decision factors. Supply Chain Management: an international journal, 11(6), p. 467-482.

Lacity, M. C. (2017). Review of 23 Years of Empirical Research on Information Technology Outsourcing Decisions and Outcomes. In Anais, Proceedings of the 50th Hawaii International Conference on System Sciences, 5214-5224.

Lacity, M. C., Khan, S. A., \& Willcocks, L. P. (2009). A review of the IT outsourcing literature: Insights for practice. The Journal of Strategic Information Systems, 18(3), 130-146.

Lacity, M. C., \& Willcocks, L. P. (1998). An empirical investigation of information technology sourcing practices: Lessons from experience. MIS quarterly, 363-408.

Lacity, M. C., \& Willcocks, L. P. (2012). Outsourcing Business and IT Services: The Evidence of Success, Robust Practices and Contractual Challenges. Legal Information Management, $12(1), 2-8$.

Laranjeira, R. M. D. (2012). Terceirização de desenvolvimento de software e modelos de contratação. 114 f. Dissertação (Mestrado em Administração) - Universidade Federal da Bahia, Salvador.

Lee, J. N. (2017). Strategic risk analysis for information technology outsourcing in hospitals. Information \& Management, 54(8). 
Lee, J. N., Huynh, M. Q., Kwok, R. C. W., \& Pi, S. M. (2003). IT outsourcing evolution: past, presente, and future. Communications of The ACM, New York, 46(5), 84-89.

Lima, E. A., Silva, F. K. P., \& Molinario, L. F. R. (2013). Fatores habilitadores para decisão de terceirização de TI: um estudo de caso no setor público brasileiro. Revista de Temas de Administração Pública, São Paulo, 8(2).

Lins, M. I. A., Duda Junior, J. S., \& Cunha, M. X. C. (2016). Terceirização de Sistemas de Informação no Setor Público: Uma Revisão Sistemática de Literatura. In Anais, 3 Workshop de Iniciação Científica em Sistemas de Informação, Florianópolis.

Martinez, A. L. (1998). Agency theory na pesquisa contábil. In Anais, 22 Encontro Nacional da Associação de Pós-Graduação e Pesquisa em Administração, Foz do Iguaçu: ANPAD, CDROM.

Mizael, G. A., Murad, C. G. C., \& Antonialli, L. M. (2020). Perspectivas da Terceirização na Administração Pública na Nova Abordagem de Contratação. Teoria e Prática em Administração, 10(1), 25-37.

Moreno, V., Coelho, M. A. S., \& Pitassi, C. (2020). Outsourcing of IT and Absorptive Capacity: A Multiple Case Study in the Brazilian Insurance Sector. Brazilian Business Review, 17(1), 97-113.

Nunes, L. F. (2018). Melhores práticas em gerenciamento de contratos terceirizados de TI: um estudo de caso em uma organização pública. $17 \mathrm{f}$. Trabalho de Conclusão de Curso (Especialização em Governança de Tecnologia da Informação) - Universidade do Sul de Santa Catarina, Santa Catarina.

Poleto, T. (2012). Abordagem multicritério para decisão de terceirização de serviço de TI. 156 f. Dissertação (Mestrado em Engenharia de Produção) - Universidade Federal de Pernambuco, Recife.

Prado, E. P. V., \& Takaoka, H. (2002). Os fatores que motivam a adoção da terceirização da tecnologia de informação: uma análise do setor industrial de São Paulo. Revista de Administração Contemporânea, 6(3), 129-147.

Santos Filho, J. L. (2009). Na corda bamba da terceirização: o caso das administrações tributárias estaduais do Brasil. 108 f. Dissertação (Mestrado em Administração de Empresas) - Universidade de Fortaleza, Fortaleza.

Sergipe Parque Tecnológico - SERGIPETEC. (online). Quem Somos. Recuperado em 05 abril, 2020, de https://sergipetec.org.br/quem-somos/. 
Silva, F. K. P. (2013). Fatores que Impactam a Decisão de Terceirização de Serviços de TI: Um estudo de Caso no Judiciário Federal Brasileiro. 183 f. Dissertação (Mestrado em Engenharia Elétrica) - Universidade de Brasília, Brasília.

Tadeu, J.C., \& Guimarães, E. H. R. (2017). O Desafio dos Gestores na Superação dos Riscos Inerentes à Gestão da Terceirização: Estudo de Caso em uma Instituição Federal de Ensino. REUNIR: Revista de Administração, Contabilidade e Sustentabilidade, 7(1), 4964.

Trantopoulos, K., Krogh, G. V., Wallin, M. W., \& Woerter, M. (2017). External Knowledge and Information Technology: Implications for Process Innovation Performance. MIS Quarterly, 41(1), 287-300.

Yin, R. (2015). Estudo de Caso: Planejamento e Métodos. (5a ed.). Porto Alegre: Bookman.

Submetido em: 20.07 .2020

Aceito em: $\quad 20.12 .2020$ 